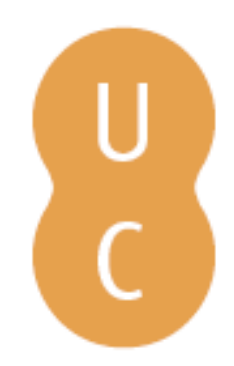

\title{
pombalina
}

\section{O mito de Orpheus: a plasticidade do mito nas vozes de Virgílio, Vinícius e Camus}
Autor(es):
Santos, Elaine C. Prado dos
Publicado por: $\begin{aligned} & \text { Associação Portuguesa de Estudos Clássicos; Imprensa da } \\ & \text { Universidade de Coimbra }\end{aligned}$

URL

persistente:

URI:http://hdl.handle.net/10316.2/31842

DOI:

DOI:http://dx.doi.org/10.14195/978-972-98142-2-8_21

Accessed : $\quad$ 26-Apr-2023 03:14:08

A navegação consulta e descarregamento dos títulos inseridos nas Bibliotecas Digitais UC Digitalis, UC Pombalina e UC Impactum, pressupõem a aceitação plena e sem reservas dos Termos e Condições de Uso destas Bibliotecas Digitais, disponíveis em https://digitalis.uc.pt/pt-pt/termos.

Conforme exposto nos referidos Termos e Condições de Uso, o descarregamento de títulos de acesso restrito requer uma licença válida de autorização devendo o utilizador aceder ao(s) documento(s) a partir de um endereço de IP da instituição detentora da supramencionada licença.

Ao utilizador é apenas permitido o descarregamento para uso pessoal, pelo que o emprego do(s) título(s) descarregado(s) para outro fim, designadamente comercial, carece de autorização do respetivo autor ou editor da obra.

Na medida em que todas as obras da UC Digitalis se encontram protegidas pelo Código do Direito de Autor e Direitos Conexos e demais legislação aplicável, toda a cópia, parcial ou total, deste documento, nos casos em que é legalmente admitida, deverá conter ou fazer-se acompanhar por este aviso.

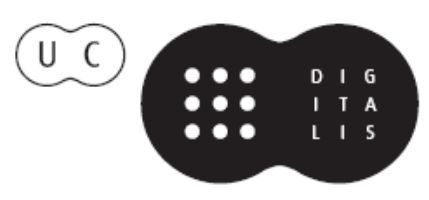




\section{Espaços e Paisagens}

\section{Antiguidade Clássica e Heranças Contemporâneas}

Vol. Il Línguas e Literaturas. Idade Média. Renascimento. Recepção

Francisco de Oliveira, Cláudia Teixeira, Paula Barata Dias (Coords.)

IMPRENSA DA UNIVERSIDADE DE COIMBRA 


\title{
O MITO DE ORPHEUS. A PLASTICIDADE DO MITO NAS VOZES DE VIRGÍLIO, VINÍCIUS E CAMUS
}

\author{
Elaine C. Prado dos Santos \\ Universidade Presbiteriana Mackenzie
}

\begin{abstract}
The myth of Orpheus was explored and retaken in almost all forms of artistic manifestations. The mythic creation, properly understood, consists in giving new senses to ancient myths. The present study proposes not only the presentation of the myth of Orpheus in the Georgics, by Vergilius, in a comparative line with the play Orfeu da Conceição, by Vinícius and with the movie Orfeu Negro (1958), by Camus; based on the theoretical subsidies of parody formulated by Hutcheon, but also the verification, in such analysis, of how the dialogic relations between different universes is established.
\end{abstract}

Keywords: Georgics, myth of Orpheus, Orfeu da Conceição, Orfeu Negro, Vergil.

Palavras-chave: Geórgicas, mito de Orfeu, Orfeu da Conceição, Orfeu Negro, Virgílio.

Um dos mitos que excedeu as fronteiras do tempo, simbolizando a celebração da imortalidade da poesia, é o de Orfeu, cuja transposição para quase todas as formas de manifestações artísticas comprova sua atemporalidade. De Virgílio a Vinícius e a Camus, o mito de Orfeu demonstra plasticidade, ao se revestir de formas mais modernas e diversificadas.

A partir dos conceitos da paródia formulados por Hutcheon, a proposta deste trabalho visa não só a apresentar o mito de Orfeu, nas Geórgicas de Virgílio (I a.C.), em uma linha comparativa com a peça Orfeu da Conceição (1956) de Vinícius de Moraes e com o filme Orfeu Negro (1958) de Marcel Camus, mas também verificar como se estabelecem as relações dialógicas entre esses universos e demonstrar que o mito é recriador.

Muitos teóricos da paródia remontam a raiz etimológica do termo ao substantivo grego parodia, que quer dizer "contra canto". Conforme Hutcheon 1985: 47, a natureza textual ou discursiva da paródia é evidente no elemento odos, que significa canto. $\mathrm{O}$ prefixo para tem dois significados, mas geralmente apenas um é mencionado, o de delinear. A paródia é uma repetição que inclui diferença, uma imitação com distância crítica. Sob essa perspectiva, pretendese verificar como se estabelece a paródia nos universos: Orfeu da Conceição e Orfeu Negro a partir do poema das Geórgicas de Virgílio, que será apreciado por esta comunicadora como texto fonte.

O poeta latino, Publius Vergilius Maro, no IV canto das Geórgicas, poema didático sobre a terra, apresenta a apicultura em um quadro agrícola, ilustrando 
o mito de Orfeu, a fim de retratar a verdade eterna do mito que se pode reencontrar na natureza.

Vinícius, inspirado na tradição clássica, escreveu a peça Orfeu da Conceição, que é uma modernização do mito grego ao ambiente de uma favela carioca. A tradição lendária estabelece a dupla ligação de Orfeu com Apolo, deus do Sol e com Dioniso, deus do vinho. Em sua versão, Vinícius deu ênfase às relações entre essas duas instâncias - apolínea e dionisíaca - no quadro específico da cultura brasileira.

No filme Orfeu Negro, o mito é transposto para o universo da favela da Babilônia, no Rio de Janeiro. Por meio desse deslocamento, Camus dessacraliza o mito, em uma aproximação ao mundo da favela, instaurando uma nova leitura, pois tudo o que é ideal e sublime é transferido para o plano material.

Vinícius e Camus utilizam acréscimos ao mito que estão presentes na cultura brasileira: favela, carnaval e samba, empregando, nessa recriação mítica, a paródia não só para enaltecer as particularidades oriundas do Brasil, mas também para criticar socialmente valores que o ser humano deixou para segundo plano.

No mito, Orfeu, possivelmente de origem trácia, era filho da musa Calíope e do rio Eagro, que, freqüentemente, é substituído por Apolo. Nas Geórgicas, o apicultor Aristeu tentou violentar Eurídice, que, em sua fuga, morreu picada por uma serpente. E como castigo, Aristeu perdeu suas abelhas. O músico e cantor, Orfeu, desesperado, desceu aos Infernos para trazer a esposa de volta. Com sua divina voz, encantou o mundo ctônico, pois a lira comoveu Caronte, que largou o barco e seguiu o cantor; Cérbero emudeceu suas três goelas abertas (Geo. IV, 471-484); os tormentos eternos ficaram, por um instante, imobilizados diante da maravilhosa voz de Orfeu (Geo. IV, 481-484).

Comovidos com a voz de Orfeu, os deuses, Plutão e Prosérpina, concordaram em devolver-lhe a esposa, entretanto uma condição foi imposta: ele iria à frente e ela lhe acompanharia os passos. Orfeu não poderia olhar para trás, mas não resistiu, ao olhar, perdeu Eurídice. Inconsolável, passou a repelir todas as mulheres da Trácia, as Mênades, que se sentiram desprezadas por tal fidelidade à esposa, mataram-no e esquartejaram-no e lançaram-lhe os restos e a cabeça no rio Hebro. Ao rolar a cabeça no rio, sua boca proferiu o nome de Eurídice (Geo. IV, 526-527).

O episódio da descida de Orfeu ao mundo dos mortos revela, em um sentido clássico, uma reflexão sobre a morte e a continuidade da tradição multissecular, que atribuía à música e ao canto poderes mágicos que transcendiam a vontade dos próprios deuses.

Nas Geórgicas, Orfeu e as abelhas estão ligados pela simbologia de sobrevivência após a morte. Os antigos pensavam que elas nasciam espontaneamente das entranhas dos touros imolados em honra dos deuses (Geo. IV, 281-285) de tal forma que Virgílio declara genus immortale manet (Geo.IV, 208).

Vinícius não apresenta a sociedade das abelhas; no entanto, apresenta Aristeu como um apicultor e relata o canto poético de Orfeu carregado de 
mel. No filme, não há qualquer referência às abelhas, ao mel e à personagem Aristeu.

$\mathrm{Na}$ peça, o mulato Orfeu mora em um barraco, não toca lira, mas toca divinamente violão, cujo som será apresentado como um contraste a barulhos desordenados, associados à ameaça do caos. Em sua apresentação, Orfeu surge brilhante no meio da noite, referência à sua natureza apolínea. Segundo observações de Vinícius, as festas e os rituais dos negros pareciam muito com os rituais gregos, marcados pelo lado dionisíaco da vida. Vinícius demonstra os traços da cultura popular que deveriam ser reelaborados com a música de Orfeu. Assim o grego da Trácia virou o negro da favela, que amava a mulata mais bonita do morro, Eurídice. Por inveja, Aristeu matou, com um punhal, Eurídice, o lado sublime de Orfeu.

No filme, o mulato Orfeu é um motorneiro de bonde, um jovem talentoso compositor, que mora na favela da Babilônia e que está se preparando para o Carnaval. Na desconstrução, por meio da paródia, Vinícius e Camus carnavalizam o mito, não como uma negação ao que está sendo parodiado, mas como objeto de reconstrução. Para Hucheon 1985:146, a paródia é hoje dotada do poder de revitalizar. Camus realiza um painel folclorizado da vida do morro carioca, o filme focaliza unicamente a comunidade negra e favelada, em uma primeira seqüência de Carnaval, em poucos momentos aludindo a outras facetas da vida local, sugerindo um contraste entre a modernidade e o ambiente anárquico do morro.

Em Camus, Eurídice é perseguida pela Morte, um homem fantasiado, lembrando a figura de Arlequim. Em sua fuga, assustada, Eurídice morre eletrocutada por um dos fios de alta tensão de uma estação de trem. Tanto na peça quanto no filme, Eurídice é associada a um princípio de organização da existência individual e do cosmos - que, aliás, reflete o que o próprio Orfeu representa para a comunidade. Esse traço se mantém e é reforçado na versão cinematográfica: sua inocência contrasta com as mulheres do morro. As implicações do sentido ritual do Carnaval não se perdem de vista em vários detalhes no desenvolvimento da narrativa fílmica que procura acentuar o dionisismo que Vinícius dizia ter descoberto na cultura negra.

Nas Geórgicas, ele canta e toca sua lira envolvendo todos com o poder mágico de sua voz. Em Orfeu da Conceição, ele sempre traz o violão a tira colo. Tudo aprendera com seu mestre, o pai Apolo, que na mitologia, é o deus do Sol e da inspiração poética. Em Orfeu da Conceição, Apolo é aquele que só sabe beber no botequim.

No filme, Orfeu também toca violão, encantando a todos os moradores e a todas as mulheres, com a sua música. Ao desfilar no Carnaval, Orfeu dança representando o Sol, uma alusão ao deus Apolo. As crianças acreditam que Orfeu consegue, com sua voz e com seu violão, fazer o Sol se levantar todas as manhãs.

Em Vinícius, Orfeu entra, com o seu canto poético, no inferno, retratado como o Clube dos Maiorais. Todos dançam e cantam; no entanto, quando o som cristalino do violão de Orfeu corre escalas dulcíssimas, todas as figuras 
presentes se imobilizam diante dele. Com sua voz, as mulheres repetem o nome da amada. Os deuses ctônicos, em Vinícius, são invertidos para os mais comuns dos mortais: Plutão, o inflexível presidente dos Maiorais do Inferno e Prosérpina, a rainha bêbada.

Orfeu, ao saber da morte de Eurídice, no filme, a procura por toda parte. Ao chegar ao local dos desaparecidos, no décimo segundo andar de um edifício, encontra um vasto corredor com muitos papéis espalhados pelo chão e um faxineiro que varre toda aquela papelada. $\mathrm{O}$ décimo segundo andar é uma sugestão aos doze deuses do Olimpo, provavelmente abandonados a um arquivo morto. $\mathrm{O}$ faxineiro, como o mítico barqueiro Caronte, conduz Orfeu ao Inferno. Desenha-se a catábase, segundo o cineasta, quando Orfeu desce os inúmeros degraus de uma sinuosa escadaria.

Nas Geórgicas, Cérbero, o cão dos infernos, emudece diante da voz maravilhosa de Orfeu. $\mathrm{Na}$ peça, no Clube do Inferno, Cérbero, o leão-dechácara, recua dominado pelo toque da música de Orfeu. No filme, Cérbero, um cão que fica na entrada de uma casa de Candomblé, permite a passagem de Orfeu.

O inferno de Camus é retratado como uma casa de Candomblé, iluminada por um tom avermelhado, onde acontece um ritual religioso, no qual não se ouvem os sons harmoniosos da cítara, mas homens e mulheres dançam, invocando as entidades. Projeta-se, na cena, uma velha, que, com a voz de Eurídice, pede a Orfeu que não olhe para trás, mas ele mais uma vez não resiste.

Vinícius substituiu o Hades pelo clube dos Maiorais e Camus por uma casa de Candomblé, para atualizar, por meio do mito, esse tipo de cultura. O canto, por sua eficácia, consegue, por uma vez vencer a morte. A perda da amada aconteceu não pela impotência do canto e sim pela dementia causada pelo amor (Geo. IV, 488). Nas Geórgicas, Orfeu foi imprudente, olhou para trás e perdeu Eurídice (Geo. IV, 491-492). Em Orfeu da Conceição, o músico se afasta de costas em direção à porta de saída. Em Orfeu Negro, uma senhora pede que Orfeu não olhe para trás.

Conforme Brandão 1991: 143, Orfeu poderia ter trazido Eurídice de volta, se não tivesse olhado para trás, pois ao olhar para trás, transgride as direções. Partiu-se a harmonia, só reconquistada se houver um retorno perfeito.

Virgílio exprime sua piedade por Orfeu, quando perde Eurídice, abrindo-se um cenário de breves interrogações (Geo. IV, 494-495). Em Vinícius, o coro se apieda de Orfeu. Em Orfeu Negro, há o acréscimo de Hermes, o vigia da estação e amigo de Orfeu, que o consola, indicando o caminho para o necrotério.

Nas Geórgicas, Eurídice é levada por uma imensa noite (Geo. IV, 498). Na peça, ela é levada pela gigantesca Dama Negra. No filme, ela é perseguida pelo Arlequim durante a noite de carnaval. A figura arlequinal, já ambígua e efêmera, é projetada, no filme, com um lado muito sombrio, por representar a imagem da morte que mata Eurídice, a sublime alma de Orfeu. Tanto a 
Dama Negra quanto Arlequim, somados ao mito, têm a função de representar a morte e conduzir Eurídice ao inferno.

Impotente para lutar contra a morte, tanto nas Geórgicas quanto na peça e no filme, ao sair dos infernos sem Eurídice, Orfeu prefere a solidão. Nas Geórgicas (Geo. IV, 507-510), Orfeu, no bosque, canta para os animais e em Orfeu da Conceição ele anda, na mata, como alma penada. Vinícius registra a desarmonia com a morte de Eurídice: sem Orfeu, no morro, não há mais violão. No filme, ele carrega o corpo de Eurídice em seus braços, subindo o morro carioca. Durante todo percurso, com uma música, agradece o amor à amada, enquanto um caminhão lava a rua, como um rito de purificação. Para Chevalier 1994: 15-18, as águas precedem a criação, é evidente que elas continuem presentes para a recriação. Ao Orfeu novo, que sobe o morro com Eurídice nos braços, corresponde a aparição de outro mundo renovado.

Segundo Brandão 1997: 114, a descida aos infernos configura o supremo rito iniciático: a catábase, a morte simbólica, é a condição para uma anábase, uma escalada definitiva na busca da anagnórisis, do autoconhecimento, da transformação do que resta do homem velho no homem novo. No filme, registram-se estes três momentos: a descida de Orfeu para resgatar Eurídice, sua morte simbólica, pegá-la em seu colo, e fazer sua anábase, subir o morro e buscar a anagnórisis: a lapidação e a harmonia de seu lado apolíneo.

Em Vinícius, as mulheres bêbadas, guiadas por Mira, em orgia, atiramse sobre Orfeu, com facas e navalhas. Como um Laocoonte, ao receber um castigo divino, Orfeu luta para desvencilhar-se da pena humana. As mulheres, na peça, não jogam a cabeça de Orfeu no rio; no entanto, Mira arremessa seu violão, atirando-o longe. Ouve-se o bater do instrumento e depois a música de Orfeu se afirma límpida. No filme, as mulheres, em um ritual de loucura, incendeiam alguns barracos. Ao ver Orfeu com Eurídice nos braços, Mira, em um ato de fúria, atira-lhe uma pedra, matando o cantor Orfeu.

Nas Geórgicas, Aristeu cumpre ritos expiatórios e a vida renasce para suas abelhas (Geo. IV, 557-558). Em Orfeu da Conceição, Vinícius acrescenta ao mito um grupo de meninos engraxates que batem em suas caixas, tocando músicas de Orfeu, exemplificando a continuidade da vida. Em Orfeu Negro, está implícita a idéia do renascer. Após a morte de Orfeu, os meninos pegam o violão para fazer o Sol se levantar. Diante deles, o Sol ressurge e uma das crianças faz o seguinte comentário: "você fez o Sol se levantar, agora você é Orfeu”. Para Eliade 1991:77, a noite da qual nasce o sol todas as manhãs simboliza o caos primordial, e o nascer do sol é uma réplica da cosmogonia.

Em Vinícius, o cantor é sempre apresentado todo de branco, cantando, sob a luz do luar. Conforme Chevalier 1994: 141, o branco é uma cor privilegiada dos ritos de iniciação: morte e renascimento. Já o vermelho é a cor do sangue. É interessante a apresentação da Dama Negra: gigantesca negra velha, envolta até os pés em um manto branco, trazendo um ramo de 
rosas vermelhas. No filme, Mira, noiva de Orfeu, aparece muitas vezes com uma rosa vermelha entre os seios.

Nos ritos de iniciação, o branco é a cor da primeira fase, a luta contra a morte, mas pode ser visto como a cor do leite materno. Luz da prata e da lua, em sua ronda completa, o leite é o arquétipo da mulher fecunda. Na peça, Orfeu olha para a lua e diz: "O mundo é todo leite/ Leite da lua, e a lua és tu, Eurídice".

Tanto Vinícius quanto Camus, em uma nova linguagem, reatualizam o mito nas condições históricas da sociedade brasileira, mostrando a existência de mitos nos tempos modernos, que são transformados e humanizados.

Virgílio, ao escrever sobre a apicultura, uniu as abelhas ao mito de Orfeu. A abelha é símbolo da ressurreição; o mel da força vital e da imortalidade. Os gregos representaram a abelha por Melissa, que figuradamente significa poeta. Orfeu, por meio do poder de seu canto, vence a própria morte. Se, numa segunda vez, perde Eurídice para sempre, é pela Dementia, pela paixão avassaladora que está dentro do ser humano. Entretanto, as abelhas renascem da própria morte, do sangue putrefato de um boi (Geo. IV., 208). Em Orfeu da Conceição, os meninos cantam as músicas de Orfeu. $\mathrm{O}$ violão mesmo despedaçado retrata sua música límpida.

....Eurydicen nox ipsa et frigida lingua

Ah! Miseram Eurydicen anima fugiente nocabat;

Eurydicen toto referebant flumine ripae ${ }^{1}$. (Geo. IV, 525-527)

Segundo Vinícius, "Só não morre no mundo a voz de Orfeu”, a voz do poeta continuará clamando pela eternidade e fará o Sol se levantar todos os dias com a música, com a poesia e com o amor.

\section{Bibliografia}

J. de Souza Brandão (1991), Mitologia grega. 4a ed. Petópolis: Vozes, v. 2. (1997), Mitologia grega. 7a ed. Petópolis: Vozes, v. 3.

Jean Chevalier; Alain Gheerbrant (1994), Dicionário de simbolos. Coord.

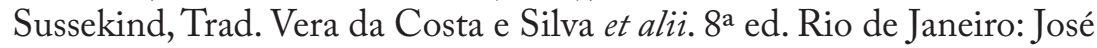
Olympio.

Mircea Eliade (1991), Mito e realidade. Trad. Póla Civelli. 3a. ed. São Paulo: Perspectiva.

(2001), O sagrado e o profano, Trad. Rogério Fernandes. 5a . ed. São Paulo: Martins Fontes.

Linda Hutcheon (1985), Uma teoria da paródia. Ensinamento das formas de arte do século XX. Lisboa: Edições 70.

\footnotetext{
${ }^{1}$ A própria voz e a lingua fria, enquanto a alma fugia, chamava Eurídice, ab! Triste Eurídice! As margens ecoavam Eurídice, ao longo de todo rio.
} 